\title{
Segurança Alimentar e Nutricional no Brasil: uma análise em perspectiva histórica
}

Volmir Ribeiro do Amaral ${ }^{1}$

David Basso ${ }^{2}$

\begin{abstract}
Resumo
Este artigo analisa a evolução teórico-conceitual da segurança alimentar e nutricional no Brasil e a construção e implantação das principais políticas públicas nesta área, entre 1985 e 2015, bem como evidencia as diferentes incursões desta temática na agenda governamental brasileira e as interações estabelecidas entre governo e sociedade civil. Esta pesquisa utilizar-se-á da revisão literária, para fins de subsidiar a construção analítica do texto, apoiando-se também em dados e relatórios técnicos de órgãos de pesquisa ligados ao tema. Realizando as análises, conclui-se que o Brasil sempre manteve iniciativas na área da segurança alimentar e nutricional, mais ou menos organizadas e em níveis de intensidade que variaram de acordo com cada período histórico, mas foi a partir dos anos 2000 que surgiu um conjunto de leis, políticas e ações que, articuladas entre si e num processo de governança participativa com os atores envolvidos, colocaram a temática num outro patamar, tanto em termos teórico-conceitual quanto de efetividade prática, possibilitando que se vislumbre e se avance no sentido da consolidação das políticas públicas nesta área.
\end{abstract}

Palavras-chave: Alimentação adequada. Direitos sociais. Fome Zero. Políticas Públicas.

\begin{abstract}
This article analyzes the theoretical and conceptual evolution of food and nutrition security in Brazil and the construction and implementation of major public policies in this area between 1985 and 2015, and highlights the different incursions of this issue in the Government agenda and the interactions established between government and civil society. This research will be using the literature review for the purpose of subsidizing the analytical construction of the text, also backing up data and technical reports from research institutions linked to the theme. Performing the analysis, it is concluded that Brazil has always maintained initiatives on food and nutrition securi-

\footnotetext{
${ }^{1}$ Mestrando do Programa de Pós-Graduação em Desenvolvimento da Universidade Regional do Noroeste do Estado do Rio Grande do Sul (UNIJUÍ).volmirdoamaral@gmail.com

${ }^{2}$ Doutor em Desenvolvimento, Agricultura e Sociedade pela UFRRJ. Professor do Departamento de Ciências Administrativas, Contábeis, Econômicas e da Comunicação (DACEC-UNIJUÍ), integrante do Corpo Docente do Programa de Pós-graduação em Desenvolvimento Regional da UNIJUÍ. E-mail: davidbasso@unijui.edu.br
} 
ty, more or less organized and intensity levels that varied according to each historical period, but it was from the 2000s that came a set laws, policies and actions, coordinated among themselves and in a participatory governance process with stakeholders, have put the issue to another level, both in theoretical and conceptual terms as practical effectiveness, making it possible to glimpse and make progress towards consolidation of public policies in this area.

Keywords: Adequate food. Social rights. Zero Hunger. Public policy.

\section{Introdução}

Este estudo aborda a evolução teórico-conceitual da Segurança Alimentar e Nutricional (SAN) no Brasil, bem como analisa as diferentes incursões deste tema na agenda governamental brasileira. De modo mais específico, analisa como o governo federal vem percebendo e assumindo a questão da SAN nas três últimas décadas; elenca as principais políticas lançadas neste período; destaca as diferentes interações estabelecidas entre governo e sociedade civil nesta área e ressalta a contribuição da sociedade civil organizada na construção das políticas de SAN.

A presente pesquisa utilizar-se-á da revisão literária, a fim de subsidiar a construção analítica da temática, apoiando-se também em dados, documentos e relatórios de órgãos de pesquisa e organizações envolvidas com o assunto.

A formulação do conceito de SAN, assim como as políticas nesta área, não aconteceu de um dia para outro, não foi tranquila e nem representou ou representa um grande consenso no Brasil. As definições atuais acerca do tema derivam de anos de discussões, embates, experiências e pesquisas. O conceito de SAN, a exemplo de outros, permanece em constante aperfeiçoamento, à luz das diferentes concepções que o cercam. Isso significa que compreensões distintas da exposta aqui sobre SAN não deixam de existir, aliás, coexistem e, por vezes, se refletem no modo de pensar e implantar ações nesta área.

As principais definições sobre SAN no Brasil foram construídas e expressadas em grandes momentos de debate e de síntese, como em conferências sobre alimentação e nutrição; na aprovação de leis; na elaboração de documentos sobre o tema e na formulação e implantação de experiências na área. Alguns desses momentos de debate e síntese serão evidenciados neste texto como forma de melhor explicitar a construção dessa trajetória. Neste sentido, o objetivo deste estudo é analisar a evolução teórico-conceitual da SAN no Brasil, entre 1985 e 2015, bem como evidenciar as diferentes incursões deste tema na agenda governamental e as interações estabelecidas entre governo e sociedade civil.

A questão da segurança alimentar sempre foi motivo de preocupação para diferentes povos, em diferentes períodos históricos. A título de exemplo, nas reduções jesuítico-guaranis, seus habitantes "[...] faziam as suas roças de 
milho, mandioca, feijão, abóbora, fumo e algodão" (CHRISTENSEN, 2001, p. 46), demonstrando claramente a importância que davam para a questão alimentar. Esse mesmo autor relata que "Todas as produções das lavouras e estâncias pertenciam à comunidade. Os bens de consumo eram distribuídos igualmente entre todos" (CHRISTENSEN, 2008, p. 17).

Os quilombolas são outro exemplo de preocupação com a segurança alimentar. Além de lutarem por liberdade, em seus refúgios, os negros “[...] reorganizavam sua vida comunitária e partilhavam entre todos o que era produzido pelas famílias" (MOURA, 2004, p. 110). Semelhante preocupação os imigrantes europeus tiveram ao chegarem ao sul do Brasil. Com base em trabalhos cooperados, priorizaram a produção de alimentos de primeira necessidade como meio de sobrevivência nas novas terras. Esses exemplos evidenciam que, em momentos e contextos distintos, a preocupação ${ }^{3}$ de como dispor de alimentos suficientes, bem como garantir-lhes o acesso para todos, permanece ao longo da história das nações e povos.

A abordagem da temática neste artigo está dividida em três momentos: no primeiro, evidencia-se o contexto e as iniciativas sob as quais surgiu, no Brasil, o termo segurança alimentar e nutricional, e como se deram as abordagens pelo governo federal e a sociedade civil nas décadas de 1980 e 1990.

Em seguida, aborda-se a temática no contexto da virada do milênio, sob a influência de iniciativas na área da SAN que o governo federal e a sociedade civil passaram a implantar nesse período, onde se destaca o Projeto Fome Zero (PFZ) e seus desdobramentos.

Num terceiro momento, procura-se visualizar alguns desafios atuais e futuros na área da SAN, onde se evidencia a necessidade de se repensar os atuais sistemas de produção e consumo, de uma maneira geral, bastante insustentáveis.

Após a sistematização de diversas informações sobre o tema e da realização de determinadas análises, algumas conclusões são apresentadas, numa tentativa de sintetizar os principais fatos e abordagens que demarcaram a trajetória da SAN no Brasil e também de apontar aspectos dentro da temática que podem ser aprofundados em outros estudos.

\section{A segurança alimentar e nutricional nas décadas de 1980 e 1990}

A partir de meados dos anos de 1980, emergem no Brasil várias mobilizações e movimentos sociais com reivindicações diversas, que vão desde a redemocratização do país, passando pela ampliação de direitos, até a luta pela redução das desigualdades sociais. Neste contexto de efervescência social, a luta por políticas de combate à fome e à pobreza ganha força no país.

\footnotetext{
${ }^{3}$ Mais informações sobre a preocupação histórica dos povos com a segurança alimentar podem ser obtidas em Pinheiro (1998, 1999a, 1999b, 1999c), Cepis (2004) e Mazoyer e Roudart (2010).
} 
Apesar da preocupação de alguns brasileiros, como Josué de Castro (1908$1973)^{4}$, que já abordava o problema da fome e da desnutrição desde a década de 1930, o surgimento do termo segurança alimentar é relativamente recente no Brasil. A expressão surge no âmbito de dois eventos ocorridos em meados da década de 1980: um foi o lançamento, em 1985, de uma proposta de Política Nacional de Segurança Alimentar por técnicos e pesquisadores ligados ao Ministério da Agricultura, e o outro foi a realização da I Conferência Nacional de Alimentação e Nutrição (I CNAN) em 1986.

A proposta da Política Nacional de Segurança Alimentar tinha como foco principal o abastecimento alimentar, isto é, a preocupação em atender às necessidades alimentares da população, bem como garantir a autossuficiência nacional na produção de alimentos, apontando no sentido de que as políticas de segurança alimentar fossem coordenadas por um conselho nacional (PINHEIRO, 2009a). Já as proposições da I CNAN, entre outros aspectos, refletiam sobre a necessidade de incorporar o elemento nutricional no debate e no conceito de segurança alimentar e da alimentação se tornar um direito humano. Promovida pelo Instituto Nacional de Alimentação e Nutrição (Inan), a Conferência teve uma única edição, mesmo assim configurou-se como um evento importante e precursor no debate sobre SAN no país.

Mesmo que o termo segurança alimentar tenha surgido, no Brasil, somente em meados dos anos de 1980, isso não significa que anteriormente não houvesse preocupações com a segurança alimentar, ou de que o país não sofresse influência, ou não influenciasse nas discussões mundiais sobre o assunto, pois o Brasil sempre manteve um papel relativamente ativo neste tema internacionalmente (IPEA, 2014). De acordo com Leão (2013), "A evolução conceitual ocorre tanto em âmbito internacional quanto nacional e caracteriza-se como um processo contínuo que acompanha as diferentes necessidades de cada povo e de cada época" (LEÃO, 2013 , p. 13). Anteriormente a este período, as discussões enfatizavam mais a ideia do combate à fome e à desnutrição, sendo que a terminologia segurança alimen-

\footnotetext{
${ }^{4} \mathrm{O}$ médico, geógrafo, cientista social e político, foi um dos primeiros brasileiros a abordar o problema da fome no país. Seus inquéritos alimentares e nutricionais possibilitaram conhecer mais as condições de vida e alimentação dos trabalhadores. Seus estudos impulsionaram a criação, na década de 1940, do salário mínimo no Brasil. Corajosamente à época, Josué de Castro mostrou o problema da fome à sociedade brasileira, colocando-o, de certa forma, na "ordem do dia". Em obras como Geografia da Fome, demonstra de forma consistente o equívoco em explicar a existência da fome como resultado da natureza, das contingências de clima, como obra do destino ou, então, como algo exclusivo de regiões ou países pobres (CASTRO, 1984). Foi um dos primeiros brasileiros a caracterizar a fome como um problema social e político, resultante da pobreza, e não da insuficiência de alimentos ou de efeitos naturais (MIELITZ, 2014). Além de seu engajamento no Brasil, Josué de Castro contribuiu internacionalmente na temática da alimentação e nutrição. Em 1947, tornou-se membro do Comitê Consultivo Permanente de Nutrição da FAO. Entre 1952 a 1956, presidiu o Conselho Executivo da FAO (IPEA, 2014). Em 1947, auxiliou na fundação da Associação Mundial de Luta Contra a Fome (Ascofam). Em 1964, com a ditadura militar no Brasil, teve seus direitos políticos cassados e exilou-se na França, onde faleceu em 1973.
} 
tar e nutricional passa a ser usada algum tempo depois ${ }^{5}$. Isso demonstra que, em comparação ao plano internacional, o conceito aqui surge mais tardiamente (VILLA REAL, 2011).

No contexto da realização das primeiras conferências de alimentação e nutrição e de segurança alimentar e dos preparativos do Brasil à Cúpula Mundial da Alimentação $(\mathrm{CMA})^{6}$ de 1996, em Roma, o conceito de SAN mais evidenciado é o que a define como sendo,

A garantia, a todos, de condições de acesso a alimentos básicos de qualidade, em quantidade suficiente, de modo permanente e sem comprometer o acesso a outras necessidades básicas, com base em práticas alimentares que possibilitem a saudável reprodução do organismo humano, contribuindo, assim, para uma existência digna (MACEDO et al., 2009, p. 36).

A década de 1990, no Brasil, foi marcada pela hegemonia política neoliberal, caracterizada, dentre outros aspectos, pela fragmentação, paralisia ou retrocesso nas políticas sociais. Apenas, como exemplo, durante o governo de Fernando Collor de Mello (1990-1992), instituições com relação direta à SAN, como a Empresa Brasileira de Assistência Técnica e Extensão Rural (Embrater) e o Inan, foram extintas ou desestruturadas. Programas ligados à alimentação foram desativados, ou sofreram grandes cortes em seus orçamentos, num contexto de enxugamento da máquina pública (IPEA, 2014)

Em meio aos graves problemas sociais que o Brasil vive neste período e do contexto instaurado pelo afastamento do presidente Fernando Collor de Mello, primeiro presidente eleito diretamente após a redemocratização do país, surge o Movimento Pela Ética na Política que, no transcorrer de suas ações e processos, amplia sua atuação para outras áreas.

\footnotetext{
${ }^{5} \mathrm{O}$ termo Segurança Alimentar e Nutricional passa a ser mais conhecido no Brasil com a Ação da Cidadania Contra a Fome, a Miséria e Pela Vida, mobilização deflagrada em 1993 com o objetivo de sensibilizar a sociedade brasileira quanto ao problema da fome e da miséria. A criação do Conselho Nacional de Segurança Alimentar e Nutricional (Consea), em sua primeira versão, em 1993, também contribui para a popularização da discussão sobre SAN. Outros momentos importantes de debate e construção de propostas na área foi a I Conferência Nacional de Segurança Alimentar, em 1994, o processo preparatório à Cúpula Mundial de Alimentação de 1996 e a criação do Fórum Brasileiro de Segurança Alimentar e Nutricional (FBSAN) em 1998.

${ }^{6}$ A decisão da Cúpula Mundial da Alimentação de reduzir até 2015 a desnutrição e a fome para a metade dos índices de 1996 foi considerada muito tímida por movimentos sociais e organizações não-governamentais que, após o evento, decidiram avançar na organização em cada país com vistas a atingir metas mais ousadas (CAISAN, 2011). Como um dos desdobramentos dessa decisão das entidades civis, no Brasil, é criado o FBSAN.

${ }^{7}$ Apenas para ilustrar o desmonte nas políticas ligadas à alimentação no período, em 1992, o Programa Nacional de Alimentação Escolar (PNAE) funcionou somente 38 dias, dos 200 dias letivos previstos. O Programa de Alimentação do Trabalhador (PAT) teve sua equipe reduzida a apenas um técnico (IPEA, 2014). Antes de desativar o Inan, foi nomeado para presidi-lo um representante da Associação Brasileira de Indústria e Nutrição (Abin), o qual passou explicitamente a priorizar os interesses da indústria alimentícia nos programas de distribuição de alimentos do governo (PINHEIRO, 2009a).
} 
O Movimento Pela Ética na Política, vitorioso na luta contra a corrupção e a impunidade, inspirou outra cruzada ética, para acabar com a fome e a miséria. Como desdobramento do movimento, surge a Ação da Cidadania Contra a Fome, a Miséria e pela Vida, com objetivo de mobilizar e, acima de tudo, sensibilizar a sociedade para a necessidade de mudanças fundamentais e urgentes, capazes de transformar a realidade econômica, política e social do País. Exatamente essa realidade que leva à exclusão, à fome e à miséria (CONSEA, 1995, p. 11-12).

O movimento da Ação da Cidadania Contra a Fome, a Miséria e Pela Vida, que tinha o sociólogo Herbert de Souza, o Betinho ${ }^{8}$, como um de seus principais expoentes, inicia uma grande sensibilização na sociedade brasileira quanto ao problema da fome e da miséria, explicitando os problemas sociais que o país vive. A Ação da Cidadania ganha adesão social e institucional, desdobrando-se, dentre outros, na formação de milhares de comitês de solidariedade e combate à fome (estimativas apontam que, no final de 1995, existiam mais de cinco mil comitês operando em todo o país), na implantação de inúmeras experiências de capacitação, geração de trabalho e renda e na criação, em abril de 1993, do Conselho Nacional de Segurança Alimentar e Nutricional (Consea) ${ }^{9}$ numa parceria com o governo Itamar Franco (TURPIN, 2008).

A necessidade da existência de um órgão de abrangência nacional e representativo da sociedade civil para tratar especificamente sobre SAN sempre esteve presente nas formulações brasileiras. Já se percebe aí um dos primeiros passos na direção de uma gestão compartilhada entre governo e sociedade civil, onde o Consea nacional representou e representa um mecanismo de governança na área da SAN (PINHEIRO, 2009a).

Com o afastamento de Collor, no segundo semestre de 1992, assume a presidência do país seu vice, Itamar Franco (1993-1994). Comparativamente ao governo anterior, o de Itamar Franco mostrou-se mais sensível com relação ao problema da fome no país, e algumas iniciativas interessantes foram tomadas, como a elaboração do Mapa da Fome, realizado pelo Instituto de Pesquisa Econômica Aplicada (IPEA), no qual foram identificadas 32 milhões de pessoas que passavam fome no Brasil. Neste contexto, também é lançado, em 1993, o Plano de Combate à Fome e à Miséria, onde os ministérios apresentaram seus compromissos de ação, tendo como objetivo articular as esferas municipal, estadual e federal e a sociedade civil, numa estratégia emergencial de combate à fome (IPEA, 2014).

\footnotetext{
${ }^{8}$ Betinho cunhou a expressão "Quem tem fome, tem pressa", procurando mostrar a urgência que populações acometidas por este problema têm. A II Conferência Nacional de Segurança Alimentar e Nutricional prestou homenagem a Betinho e a Josué de Castro, constituindo-os como patronos do Consea nacional.

${ }^{9}$ Instituído por meio do Decreto $n^{\circ} 807$, de 24 de abril de 1993, o Consea foi composto por representantes da sociedade civil e de alguns ministérios, tendo como uma das principais atribuições aconselhar a Presidência da República e apresentar propostas na área da SAN (PINHEIRO, 2009a; IPEA, 2014). A presidência do Consea fica a cargo do Bispo da Igreja Católica Dom Mauro Morelli. De acordo com Müller (2007), Macedo et al. (2009) e Ipea (2014), uma proposta "embrionária" do Conselho bem como da Política Nacional de Segurança Alimentar já tinha sido apresentada em março de 1993 ao governo de Itamar Franco pelo Governo Paralelo. A atitude receptiva de Itamar às propostas apresentadas faz com que o tema da fome ganhe certa força na agenda política à época.
} 
Em julho de 1994, o Consea e outras organizações realizam a I Conferência Nacional de Segurança Alimentar (I CNSA) ${ }^{10}$, em Brasília (DF), reunindo cerca de dois mil delegados, escolhidos a partir de uma ampla mobilização das conferências municipais, microrregionais e estaduais e comitês setoriais. A Conferência configurou-se num dos primeiros grandes eventos, após a redemocratização do país, expressando uma grande pluralidade de organizações e diversidade de pensamento. Com o tema "Fome: uma questão nacional", a Conferência, além de fazer um balanço das ações em curso na área e do trabalho do Consea, também aponta para a necessidade de o país ter uma política nacional de segurança alimentar.

Naquele contexto, apontou-se a concentração da renda e da terra como principais fatores à existência da fome e da miséria no país (IPEA, 2008). Nessa perspectiva, discussões que indicam a necessidade de mudanças estruturais se intensificam, ficando mais clara uma determinada concepção de SAN, isto é, uma compreensão que visa superar a ideia de que a fome resulta da falta de produção de alimentos ou de efeitos climáticos adversos, e busca discutir formas de como prover a população dos meios necessários para garantir a todos uma alimentação adequada e uma vida digna.

O documento final da Conferência traz o conceito de segurança alimentar como sendo

Um conjunto de princípios, políticas, medidas e instrumentos que assegure permanentemente $o$ acesso de todos os habitantes em território brasileiro aos alimentos, a preços adequados, em quantidade e qualidade necessárias para satisfazer as exigências nutricionais para uma vida digna e saudável bem como os demais direitos da cidadania (CONSEA, 1995, p. 134).

Fernando Henrique Cardoso (FHC), logo no início de seu primeiro mandato (1995-1998), lança o Programa Comunidade Solidária (PCS), vinculado à Casa Civil da Presidência da República, com o objetivo de esta ser a principal estratégia do governo no combate à fome e à pobreza. Durantes seus dois mandatos, o Consea deixou de existir, sendo implantado em seu lugar o Conselho ${ }^{11}$ do PCS (TURPIN, 2008). Apesar de sua curta duração, na primeira versão (1993-1994), o Consea incide positivamente em ações como as de distribuição de estoques públicos de alimentos a populações socialmente vulneráveis, especialmente no Nordeste, melhoria de programas como o de distribuição de leite, alimentação do trabalhador e alimentação escolar (IPEA, 2014). Também contribuiu na sensibilização da sociedade quanto ao problema da fome e da pobreza, aproximando mais governo e sociedade civil organizada. Apesar dos esforços empreendidos, naquele momento, o combate à fome e à pobreza não se tornou um objetivo estratégico do governo como um todo (INSTITUTO CIDADANIA, 2001a; IPEA, 2014).

Apesar do PCS manter algumas ações e discussões sobre SAN, principalmente através de alguns de seus comitês, o mesmo não possui a representatividade do

${ }^{10}$ Na primeira conferência, a dimensão nutricional se encontra numa fase inicial de debate no Brasil, de modo que não figura na sigla (CNSA), como nas edições posteriores (CNSAN).

11 Órgão consultivo da Presidência da República composto por dez Ministros de Estado, Secretária Executiva do PCS, Primeira-Dama Ruth Cardoso e por 21 representantes da sociedade civil, nomeados pelo presidente da república. 
Consea e não consegue tornar a SAN uma prioridade de governo. "O PCS não conseguiu apresentar uma ação essencialmente estruturante no combate à pobreza e seus flagelos sociais, como a fome e a desnutrição" (IPEA, 2014, p. 27). A fragmentação de programas em vários ministérios, critérios confusos para a aprovação dos projetos e a insuficiência de recursos corroborou para um ambiente de incerteza e instabilidade nas ações voltadas à área da SAN (IPEA, 2014).

No segundo mandato de FHC (1999-2002), o PCS sofre algumas alterações. Sua principal missão passou a ser estimular experiências de desenvolvimento local e parcerias entre governo e sociedade civil, e a função anterior, coordenar as ações de combate à fome e à pobreza, foi repassada ao Programa Comunidade Ativa (PCA). Procura-se dar uma "nova roupagem" ao PCS, porém sem grandes novidades em termos institucionais e operacionais. Na avaliação do Ipea (2014), o PCA apostara demasiadamente na capacidade de regiões pobres e marginalizadas desenvolverem dinâmicas socioeconômicas autônomas e, com isso, não se avançou na implantação de políticas públicas capazes de impulsionar essas comunidades a fim de superarem seus "ciclos viciosos" de pobreza.

Em meados do segundo mandato de FHC, têm início programas que visam atender emergencialmente populações vulneráveis, como o Programa Bolsa Alimentação, do Ministério da Saúde (MS), dirigido a crianças e gestantes vulneráveis; o Vale Gás, do Ministério de Minas e Energia (MME), e o Bolsa Escola, do Ministério da Educação (MEC) (PINHEIRO, 2009a; IPEA, 2014) ${ }^{12}$. Porém,

O fato de cada um desses programas possuir seus próprios critérios de elegibilidade, banco de dados de beneficiários e estratégias de implantação, impediu uma articulação mais efetiva entre eles e outras ações em curso para o combate à pobreza e a garantia da segurança alimentar no Brasil (IPEA, 2014, p. 30).

Um aspecto a se destacar, alcançado nos mandatos de FHC, foi o controle inflacionário que, dentre outras coisas, propiciou uma estabilidade nos preços dos alimentos, atenuando, assim, as variações que comprometiam grande parte da renda, sobretudo das camadas sociais mais pobres.

Se, por um lado, neste período de 1995 a 2002, não se obteve maiores avanços em termos de efetivação de uma proposta de segurança alimentar para o país, por outro, avançou-se significativamente na formulação conceitual sobre o tema. Num comparativo com elaborações anteriores, o documento do Brasil levado à CMA de 1996, elaborado por um grupo de trabalho, além de agregar as contribuições do Consea e das conferências até então realizadas, expressa uma formulação mais abrangente sobre o tema.

12 A partir de outubro de 2003, esses programas de transferência direta de renda foram unificados no Programa Bolsa Família (PBF), instituído através da Lei 10.836. A partir daí, o governo federal organiza o Cadastro Único para Programas Sociais do Governo Federal (CadÚnico), visando unificar critérios de elegibilidade, dados e estratégias de implementação dos mesmos. Para se tornarem beneficiários dos programas sociais do governo federal, os interessados precisam primeiro estar cadastrados no Cadúnico. 
Segurança Alimentar e Nutricional significa garantir a todos o acesso a alimentos básicos de qualidade, em quantidade suficiente, de modo permanente e sem comprometer o acesso a outras necessidades essenciais, com base em práticas alimentares saudáveis. Contribuindo, assim, para uma existência digna em um contexto de desenvolvimento integral da pessoa humana (INSTITUTO CIDADANIA, 2001a, p. 13).

Observa-se já uma formulação que aborda, no acesso aos alimentos básicos, preocupações com a qualidade, a disponibilidade, a regularidade e o estímulo a práticas alimentares saudáveis, aspectos já presentes no debate internacional. Esta formulação destaca, dentre outras questões, a "[...] articulação estabelecida entre a segurança alimentar e a segurança nutricional, como 'duas faces da mesma moeda', não se podendo garantir uma delas sem que a outra também esteja assegurada" (INSTITUTO CIDADANIA, 2001a, p. 13). A primeira se refere aos processos de disponibilidade dos alimentos, e a segunda relaciona-se com a escolha, o preparo e o consumo dos alimentos (LEÃO, 2013).

Na avaliação do Ipea (2014), a temática da SAN, nas décadas de 1980 e 1990, não chegou a se constituir numa prioridade governamental, permanecendo ligada a estruturas e programas sem autonomia de recursos, sem critérios claros de acesso, com institucionalidade frágil e sujeita a muitas descontinuidades. Contudo, nota-se, neste período, a existência de alguns avanços, decorrentes em grande medida de ações da sociedade civil e, principalmente, voltados à formulação teórico-conceitual sobre o tema, aspecto que auxiliará muito a construção e implantação de ações mais eficazes posteriormente.

\section{A segurança alimentar e nutricional a partir dos anos 2000}

No contexto da virada do milênio, as discussões em torno do combate à fome e à pobreza se intensificam no Brasil. É um momento em que a sociedade civil passa a exigir, com mais força dos governantes, a formulação e implantação de políticas de SAN mais abrangentes e eficazes. É um período em que, simultaneamente, continua-se evoluindo na formulação teórico-conceitual sobre o tema, mas também se iniciam ações importantes na área.

Num esforço de mobilização nacional, ao longo de 2001, o Instituto Cidadania, uma Organização Não-Governamental (ONG), constrói, como parte integrante do plano de governo da candidatura de Luís Inácio Lula da Silva à presidência da República, o "Projeto Fome Zero: uma proposta de política de segurança alimentar para o Brasil" ${ }^{\prime 3}$. Projeto este debatido nacionalmente e construído a muitas mãos e que, popularmente, ficou mais conhecido apenas como "Fome Zero".

${ }^{13}$ As propostas de SAN contidas no Projeto Fome Zero foram agrupadas em três eixos de políticas: (1) políticas estruturais: voltadas a combater as causas da fome e da pobreza, capazes de diminuir as desigualdades e de incluir social e produtivamente as famílias vulneráveis; (2) políticas específicas: destinadas a combater diretamente a fome e a desnutrição de famílias em situação de insegurança alimentar, de acordo com cada realidade; (3) políticas locais: implantadas através de parcerias com governos estaduais e municipais, com a iniciativa privada e a sociedade civil (INSTITUTO CIDADANIA, 2001a). 
Baseando-se em dados da Pesquisa Nacional por Amostra de Domicílios (PNAD) de 1999, o PFZ identificou, em 2001, a existência de 9,3 milhões de famílias (44 milhões de pessoas, cerca de $28 \%$ da população brasileira) vulneráveis à fome (INSTITUTO CIDADANIA, 2001a). O Projeto também identificou que as causas da fome não são conjunturais, e sim estruturais, e estão relacionadas ao modelo de desenvolvimento adotado no país. Sustenta que o problema da fome no Brasil "[...] não é a falta de disponibilidade de alimentos, mas sim o acesso a eles" (INSTITUTO CIDADANIA, 2001b, p. 19), reafirmando, de alguma forma, teses já levantadas no Brasil na década de 1990.

Dentre todo um diagnóstico produzido com relação ao problema da fome e de propostas apontadas com vistas a sua resolução, o PFZ também apresentou um conceito sobre o tema.

Segurança Alimentar e Nutricional é a garantia do direito ao acesso a alimentos de qualidade, em quantidade suficiente e de modo permanente, com base em práticas alimentares saudáveis e sem comprometer o acesso a outras necessidades essenciais e nem o sistema alimentar futuro, devendo se realizar em bases sustentáveis. Todo país deve ser soberano para assegurar sua segurança alimentar, respeitando as características culturais de cada povo, manifestadas no ato de se alimentar. É responsabilidade dos Estados Nacionais assegurarem este direito e devem fazê-lo em obrigatória articulação com a sociedade civil, cada parte cumprindo suas atribuições específicas (INSTITUTO CIDADANIA, 2001a, p. 15).

Percebe-se que, além de reafirmar noções já presentes em elaborações anteriores, a presente formulação aborda outros quatro importantes aspectos relacionados à SAN: (1) a necessidade dos países serem soberanos e, assim, terem condições de assegurar uma alimentação adequada à sua população, de acordo com suas tradições, o que significa agir no plano internacional para mudar determinadas regras comerciais que prejudicam os países em desenvolvimento; (2) o desenvolvimento de sistemas de produção mais sustentáveis, que possam assegurar qualidade de vida à atual e às futuras gerações, bem como preservar os recursos naturais; (3) a responsabilidade do Estado em garantir o direito à alimentação. Aliás, é pela primeira vez, no Brasil, que a SAN é colocada como uma atribuição do Estado e um direito dos cidadãos.

Nessa perspectiva, a SAN não deve ser vista ou praticada como assistencialismo ou caridade por qualquer um que seja. Mesmo assim, Rocha $(2004$, p. 58) alerta que "[...] consolidar e internalizar o conceito de segurança alimentar e nutricional como um direito ainda é um processo em construção na sociedade" e, como tal, sujeito a disputas; (4) necessidade de uma articulação do poder público com a sociedade civil, num trabalho integrado, onde cada um assuma responsabilidades específicas.

As discussões envolvendo a questão da fome e da pobreza no Brasil atingem certa centralidade nas eleições de 2002, quando Lula se elege presidente da república. Em seu primeiro discurso como presidente eleito, afirma que "[...] se, ao final do meu mandato, cada brasileiro puder se alimentar três vezes ao dia, terei realizado a missão de minha vida" (TAKAGI, 2010 apud IPEA, 2014, p. 31), dando sinais de que 
priorizaria em seu governo o tema da SAN.

Com o histórico favorável de seu partido no combate à fome e à pobreza, com a crescente sensibilização social com relação ao problema e com o respaldo político da eleição recente, o governo de Lula desencadeia logo de início importantes iniciativas na área, dentre elas, a criação do Ministério Extraordinário da Segurança Alimentar e Combate à Fome (Mesa) ${ }^{14}$, a recriação do Consea ${ }^{15}$ e o início de diferentes ações do PFZ.

Sem desconsiderar as ações desenvolvidas na área ao longo dos anos, com o PFZ, a partir de 2003, acontece no Brasil uma espécie de "divisor de águas" com relação à SAN. Iniciativas de mobilização social são (re)tomadas; o governo federal passa a destinar mais recursos para o setor; programas e projetos específicos são criados, ampliados ou unificados; ampliam-se as transferências de renda a públicos vulneráveis socialmente; criam-se mecanismos de gestão das políticas sociais; continuam-se os esforços teóricos e práticos na área; espaços de discussão e deliberação, como os fóruns, conferências e conselhos, passam a ser incentivados, dentre outros. Isso tudo eleva o combate à fome e à miséria no Brasil a patamares até então não experimentados. Assim, um novo referencial de políticas públicas sobre segurança alimentar e nutricional se inicia em 2003, inaugurando um novo ciclo nesta temática (ROMÃO, 2010; IPEA, 2014) 16.

A Organização das Nações Unidas para Agricultura e Alimentação (FAO) considera que o país, a partir de 2003 , com a implantação de ações estratégicas, vem obtendo resultados positivos, especialmente no combate à insegurança alimentar e à desnutrição. “O Brasil realizou grandes avanços na governança da segurança alimentar e nutricional ao longo da última década. Avanços significativos na diminuição da pobreza e da fome demonstram o êxito dessa abordagem intersetorial, participativa e bem coordenada" (FAO, 2014a, p. 9).

${ }^{14}$ Em janeiro de 2004, o Mesa foi absorvido pelo atual Ministério do Desenvolvimento Social e Combate à Fome (MDS), que também incorporou o Ministério da Ação Social (MAS) e a Secretaria Executiva do Programa Bolsa Família.

${ }^{15} \mathrm{O}$ Consea é recriado pelo Decreto 4.582, de 30 de janeiro de 2003. De acordo com o Decreto 8.226 , de 16 de abril de 2014, o Consea é atualmente composto por sessenta membros, titulares e suplentes, dos quais $2 / 3$ (dois terços) de representantes da sociedade civil e $1 / 3$ (um terço) de representantes governamentais. A representação governamental é exercida pelos titulares da Casa Civil da Presidência da República; Ministério do Desenvolvimento Social e Combate à Fome; Ministério da Agricultura, Pecuária e Abastecimento; Ministério das Cidades; Ministério do Desenvolvimento Agrário; Ministério da Educação; Ministério da Fazenda; Ministério do Meio Ambiente; Ministério do Planejamento, Orçamento e Gestão; Ministério da Saúde; Ministério do Trabalho e Emprego; Ministério da Integração Nacional; Ministério da Ciência, Tecnologia e Inovação; Ministério das Relações Exteriores; Ministério da Justiça; Secretaria Geral da Presidência da República; Ministério da Pesca e Aquicultura; Secretaria de Políticas para as Mulheres da Presidência da República; Secretaria de Direitos Humanos da Presidência da República; e Secretaria de Políticas de Promoção da Igualdade Racial da Presidência da República.

${ }^{16}$ Refletindo sobre espaços democráticos e políticas públicas na área da SAN, Zimmermann (2008) salienta que, no caso do Brasil, em geral, a construção das políticas públicas segue uma lógica, qual seja, são geradas para dar conta de um problema social, e, para que este problema social seja reconhecido pela sociedade, ele precisa se tornar um problema político importante. Na medida em que isso ocorre, aumentam as chances de se construir uma política pública. De acordo com este raciocínio, em meados dos anos 2000, parece que a questão da fome no Brasil atinge esse status de "problema político". 
Como parte deste esforço, e visando também compreender melhor a problemática da segurança alimentar no Brasil, o Instituto Brasileiro de Geografia e Estatística (IBGE), através da PNAD de 2004, inclui, pela primeira vez, um indicador de segurança alimentar e nutricional, com a finalidade de gerar informações específicas e estatísticas oficiais sobre o tema, até então inexistentes (ROMÃO, 2010).

Procurando desempenhar suas funções, o Consea nacional, já em sua nova configuração, juntamente com o MDS, realiza, em março de 2004, em Olinda (PE), a II Conferência Nacional de Segurança Alimentar e Nutricional (II CNSAN), com o tema "A Construção da Política Nacional de Segurança Alimentar e Nutricional", contando com a participação de cerca de 1.300 delegados, escolhidos em conferências municipais e estaduais que a precederam.

Depois de um interregno de 10 anos da primeira conferência nacional, acontece a segunda, a qual, de alguma forma, incorpora os acúmulos produzidos na área na última década. De acordo com Pinheiro (2009a), as discussões da II CNSAN se concentram em ações e projetos que visam assegurar o acesso à alimentação, à soberania alimentar, à qualidade alimentar, ao respeito às culturas alimentares, à busca por sistemas mais sustentáveis de produção, à institucionalização da SAN (lei, regulamentação, políticas e planos) e à alimentação como um direito humano. Cabe ainda ressaltar que nesta conferência incorporou-se, de vez, o aspecto nutricional e da qualidade alimentar.

Resultado de anos de reivindicação de organizações e movimentos sociais comprometidos com o direito humano à alimentação e dando encaminhamento a uma das principais propostas da II CNSAN, em setembro de 2006, a segurança alimentar e nutricional torna-se lei no Brasil, com a aprovação da Lei 11.346, que cria a Lei Orgânica de Segurança Alimentar e Nutricional (Losan), por meio da qual se institui o Sistema Nacional de Segurança Alimentar Nutricional (Sisan), um sistema público, com previsão de gestão intersetorial e participativa, e que visa articular os diversos setores, os três níveis de governo e a sociedade civil organizada (CAISAN, 2011). A referida Lei define como integrantes deste sistema a Conferência Nacional de Segurança Alimentar e Nutricional, o Consea nacional, a Caisan, os órgãos e entidades de SAN da união, estados, do Distrito Federal e municípios, além das instituições privadas que manifestarem interesse em aderir ao Sisan.

A Lei também institucionaliza legalmente o Consea, tornando-o permanente, o que significa um avanço institucional e organizacional importante para o setor. Com a Losan, abrem-se possibilidades de cidadãos privados de alimentação adequada cobrarem do Estado, uma vez que essa lei institucionalizou juridicamente o direito humano à alimentação. O seu art. 2oㅡ, parágrafo 2o, traz que “[...] é dever do poder público respeitar, proteger, promover, prover, informar, monitorar, fiscalizar e avaliar a realização do direito humano à alimentação adequada, bem como garantir os mecanismos para sua exigibilidade". O art. 3ํ da mesma Lei também institucionaliza um conceito de SAN. 
A segurança alimentar e nutricional consiste na realização do direito de todos ao acesso regular e permanente a alimentos de qualidade, em quantidade suficiente, sem comprometer o acesso a outras necessidades essenciais, tendo como base práticas alimentares promotoras de saúde que respeitem a diversidade cultural e que sejam ambiental, cultural, econômica e socialmente sustentáveis (BRASIL, 2006).

Esse entendimento brasileiro sobre SAN representa um grande avanço institucional, não só porque estabelece um conceito, na forma da Lei, mas também porque o aproxima das abordagens do Direito Humano à Alimentação Adequada (DHAA), apregoado internacionalmente.

Em paralelo aos avanços das políticas de SAN, outras duas importantes iniciativas ocorreram. Em 2006, dá-se a aprovação da Lei n 11.326, também conhecida como "Lei da Agricultura Familiar", que, dentre outros aspectos, caracteriza melhor quem pertence a essa categoria social, conferindo-lhe agora também o reconhecimento legal, aspecto importantíssimo para o avanço de suas políticas públicas. Em 2009, aprova-se a Lei nْ 11.947, uma nova legislação à alimentação escolar que, dentre os avanços, amplia o Programa Nacional de Alimentação Escolar (PNAE) a toda a rede pública de educação básica, inclusive a públicos especiais e tradicionais, e obriga os gestores públicos a empregarem, no mínimo, 30\% dos recursos financeiros repassados pelo Fundo Nacional de Desenvolvimento da Educação (FNDE) na compra de gêneros alimentícios diretamente da agricultura familiar e suas organizações. Essas duas leis reforçam o vínculo da agricultura familiar com a alimentação escolar e a segurança alimentar e nutricional.

Em julho de 2007, em Fortaleza (CE), o Consea e o MDS realizam a III Conferência Nacional de Segurança Alimentar e Nutricional (III CNSAN), com o lema "Por um Desenvolvimento Sustentável com Soberania e Segurança Alimentar e Nutricional", tendo cerca de 1.800 participantes, expressando uma grande diversidade de grupos sociais representados, sendo precedida de encontros preparatórios e conferências municipais, regionais e estaduais. As discussões da referida Conferência chamaram a atenção para a necessidade de consolidar a política nacional de SAN e estruturar o Sisan (ZIMMERMANN, 2008). Integrando este esforço, em 2007, através do Decreto 6.273, foi criada a Câmara Interministerial de Segurança Alimentar e Nutricional (Caisan), com a missão de articular o governo federal e os diversos órgãos envolvidos com o tema.

Em fevereiro de 2010, a alimentação alcançou status de direito social no Brasil, através da aprovação da Emenda Constitucional n 64/2010, que introduziu, no art. 60 da atual Constituição Federal, a alimentação como um direito fundamental. "São direitos sociais a educação, a saúde, a alimentação, o trabalho, a moradia, o lazer, a segurança, a previdência social, a proteção à maternidade e à infância, a assistência aos desamparados, na forma desta Constituição" (grifo nosso). Mesmo a Constituição Federal de 1988 sendo considerada a "Constituição Cidadã", a alimentação, até 2010, ainda não era constitucionalmente um direito social.

Em agosto de 2010, a Losan é regulamentada pelo Decreto $n^{\circ} 7.272$, que institui a Política Nacional de Segurança Alimentar e Nutricional (PNSAN), visando consolidá-la como uma política de estado e estabelecendo os parâmetros para a 
elaboração do Plano Nacional de Segurança Alimentar e Nutricional (PLANSAN). Em dezembro do mesmo ano, inicia-se a estruturação da Caisan, com a constituição de uma equipe mínima.

Em novembro de 2011, em Salvador (BA), realiza-se a IV Conferência Nacional de Segurança Alimentar e Nutricional (IV CNSAN), que contou com a participação de cerca de dois mil participantes. Com o lema "Alimentação Adequada e Saudável: Direito de Todos", a Conferência teve como objetivos principais construir compromissos visando à efetivação do direito humano à alimentação adequada e saudável, previsto constitucionalmente, e promover a soberania alimentar por meio da implementação da Política e do Sistema Nacional de Segurança Alimentar e Nutricional nas esferas de governo e com a participação da sociedade civil.

Elaborado pela Caisan ${ }^{17}$, em consonância com as diretrizes do Consea e da Política Nacional de Segurança Alimentar e Nutricional, em 2011, o Pleno Ministerial da Câmara aprova o primeiro Plano Nacional de Segurança Alimentar e Nutricional, o PLANSAN 2012/2015, que começa a valer a partir de janeiro de 2012, sendo este um dos principais instrumentos de planejamento, gestão e execução da PNSAN. Este primeiro PLANSAN, resultado de um pacto intersetorial que visa consolidar as conquistas obtidas até então na área da SAN e avançar nos desafios futuros, está organizado em 330 metas, 43 objetivos e oito diretrizes da Política Nacional de SAN e reúne um conjunto de ações do governo federal e dos órgãos voltados à produção, ao fortalecimento da agricultura familiar, ao abastecimento alimentar e à promoção da alimentação saudável e adequada. O período deste primeiro PLANSAN coincide com o Plano Plurianual (2012-2015) da União, fato que aumenta as possibilidades de sua implementação e intersetorialidade. Está previsto a revisão do Plano a cada dois anos, com base nas orientações da Caisan, nas propostas do Consea e no monitoramento de sua execução.

Em setembro de 2014, a FAO divulgou seu relatório anual "O Estado da Insegurança Alimentar no Mundo" (SOFI na sigla em inglês), o qual coloca o Brasil fora do mapa da fome mundial. O relatório mostra que, de 2002 a 2013, caiu em 82,1\% a população brasileira considerada em situação de subalimentação. No Indicador de Prevalência de Subalimentação, medida empregada pela FAO há 50 anos para dimensionar e acompanhar a fome em nível internacional, o Brasil atingiu nível menor que 5\%. Países abaixo desse percentual são considerados livres do problema da fome. Conforme o relatório da FAO, o Brasil possui apenas 1,7\% (cerca de 3,4 milhões de pessoas) de subalimentados, o que significa dizer que $98,3 \%$ da população brasileira têm segurança alimentar (FAO, 2014b).

${ }^{17}$ A elaboração do PLANSAN deu-se em três etapas principais: (1) construção de pré-proposta do Plano no âmbito da Caisan; (2) incorporação das contribuições da sociedade civil no âmbito do Sisan; e (3) avaliação e validação pelo Pleno Ministerial da Caisan (CAISAN, 2011). Mais informações a respeito podem ser obtidas em Caisan (2011 e 2014). 
De acordo com a FAO (2014b), algumas ações foram importantes para o Brasil atingir este resultado ${ }^{18}$, destacando-se (1) o aumento da oferta de alimentos, cujos dados apontam um crescimento, entre 2002 e 2013, de 10\% da oferta de calorias. Entre 2002 e 2012, a quantidade de produção de cereais, leguminosas e oleaginosas aumentou mais de $60 \%$. Os incentivos vinculados ao crédito rural, seguro agrícola, preços mínimos, mercados institucionais e assistência técnica contribuíram para esse aumento da produção.

Nesses 10 anos, os recursos do Programa Nacional de Fortalecimento da Agricultura Familiar (Pronaf) e do Programa de Aquisição de Alimentos (PAA) aumentaram em 10 vezes; (2) o aumento de renda das camadas sociais mais pobres. Os dados mostram que, entre 2001 e 2012, a renda dos 20\% mais pobres cresceu, relativamente, três vezes mais do que a renda dos $20 \%$ mais ricos, e o salário mínimo teve um crescimento real neste período de 71,5\%; (3) a geração de cerca de 21 milhões de empregos formais no período; (4) o Programa Bolsa Família, que beneficia atualmente cerca de 14 milhões de famílias; (5) o fortalecimento da alimentação escolar, com um atendimento em torno de 43 milhões de estudantes nos últimos anos; e (6) a participação ativa da sociedade civil e a governança compartilhada da área.

O relatório publicado no Brasil, em agosto de 2014, pela FAO, intitulado "O estado de segurança alimentar e nutricional no Brasil: um retrato multidimensional" analisa as políticas e a governança sobre a SAN, implantadas nos últimos anos no país, ressaltando que "[...] o Brasil já é hoje uma referência internacional de combate à fome. As experiências exitosas, como transferência de renda, compras diretas para aquisição de alimentos, a capacitação técnica de pequenos produtores, entre outras, está sendo transferida para outros países" (FAO, 2014a, p. 5) ${ }^{19}$. O documento da FAO também destaca o Brasil por ter priorizado o combate à fome; trabalhado a SAN na perspectiva do DHAA; articulado as várias políticas internas, mantendo-as sintonizadas com as discussões mundiais; implantado sistemas de governança sobre as ações e propiciado processos participativos e intersetoriais na área.

Entre os dias 03 e 06 de novembro de 2015, em Brasília (DF), realizou-se a V Conferência Nacional de Segurança Alimentar e Nutricional (V CNSAN), com o lema "Comida de verdade no campo e na cidade: por direitos e soberania alimentar". Participaram 1.300 delegados(as) eleitos em conferências municipais, regionais e estaduais, além de agentes públicos e convidados, onde se (re)afirmaram os direitos conquistados, a defesa da soberania alimentar e nutricional e a efetivação do direito humano à alimentação saudável para todos os povos.

Além disso, a Conferência reivindicou mais acesso à terra e à água de qualidade; a criação, qualificação e ampliação das políticas promotoras de sistemas pro-

${ }^{18}$ Como já mencionado, a Cúpula Mundial da Alimentação de 1996, com base nos índices daquele ano, colocou uma meta de reduzir pela metade a população vulnerável à fome até 2015. Passados 18 anos, o Brasil além de cumprir com a meta antecipadamente, ainda em 2014, atingiu o status de país no mundo tecnicamente livre da fome.

19 Refletindo também essas constatações da FAO, o editorial do jornal Zero Hora de 17 de setembro de 2014, destaca a importância da vitória do Brasil sobre a fome e a necessidade de se continuar com as políticas de SAN aos grupos mais vulneráveis, ressaltando que essa conquista é significativa e "um de seus méritos é o de não resultar do acaso, mas de políticas adequadas, colocadas em prática de forma sistemática e continuada". 
dutivos e de consumo sustentáveis e, de modo mais específico, o fortalecimento do Plano Nacional de Agroecologia e Produção Orgânica, visando estimular o processo de transição agroecológica e a implantação do Programa Nacional de Redução do Uso de Agrotóxicos (Pronara), objetivando a diminuição no seu uso, dado que o Brasil é o maior consumidor mundial de agrotóxico.

\section{Desafios à consolidação da segurança alimentar e nutricional no Brasil}

Apesar do volume de ações em SAN que vêm sendo desenvolvidas nos últimos anos no Brasil e dos resultados positivos destas, percebe-se a necessidade de se aprofundar as mudanças estruturais, tais como a democratização do acesso à terra e ao crédito, a melhoria da renda e o acesso às políticas sociais, como forma de dar maior consistência e perenidade às ações na área da SAN. Acredita-se que estas e outras ações estruturantes é que permitirão consolidar os avanços necessários a médio e a longo prazo.

Outro desafio que se impõe em paralelo é a busca por modelos mais sustentáveis de produção e consumo.

O momento é oportuno para se pensar em um novo projeto de desenvolvimento, que seja capaz de aliar crescimento econômico, inclusão social e sustentabilidade ambiental. [...] A transição para um novo modelo de desenvolvimento sustentável exige a modificação dos paradigmas de produção e de consumo vigentes. E, neste novo modelo, a questão da sustentabilidade é crucial (MORAIS; BORGES, 2010, p. 15).

A crítica aos sistemas insustentáveis de produção e consumo na área alimentar se intensificam na medida em que as consequências negativas do produtivismo e do desenvolvimentismo se tornam mais evidentes, tanto no que tange à destruição ambiental como em relação à qualidade dos alimentos. "O atual cenário - de escassez de recursos naturais, aquecimento global, injustiça e exclusão social - nos aponta a equação insustentável dos padrões de produção e consumo" (PAULI; ROSA, 2004, p. 24). Neste contexto de insustentabilidade, os autores indicam a necessidade de cada vez mais "suprimir o supérfluo e garantir o essencial".

Outra discussão que vem ganhando força na área da SAN, nos últimos anos, é o aspecto da qualidade alimentar e nutricional, que possui relação direta com a sustentabilidade envolvida da produção até o consumo. Isso significa dizer que é necessário pensar a alimentação para além da sua regularidade e quantidade. Os aspectos nutricionais devem ganhar cada vez mais importância na alimentação atuale futura, passando a ser, definitivamente, uma preocupação permanente das políticas públicas de produção, distribuição e consumo (VILLA REAL, 2011).

Somente após mais de meio século de Josué de Castro ter identificado o problema nutricional, que chamou de "fome oculta", é que tal preocupação começa efetivamente a ser assimilada e trabalhada. Como visto, caminha-se no sentido de agregar à segurança alimentar os aspectos nutricionais, ambientais, sociais e culturais envolvidos na alimentação. Elementos de maior grau de complexidade passam a ser incorporados ao conceito de SAN, e, por conta disso, sua efetivação nesses 
termos se torna cada vez mais desafiadora.

Combinadamente com os desafios já mencionados, há ainda a necessidade de se implantar um amplo e consistente processo de (re)educação alimentar no Brasil. Estudos (MDS, 2005; BARROS, 2008; ARANCIBIA, 2012) evidenciam que o país está vivendo uma transição alimentar e nutricional, cujos indicadores mais preocupantes são os altos índices de sobrepeso e obesidade. O fato positivo de parcelas socialmente mais vulneráveis de outrora passarem a ter acesso a uma alimentação regular e em quantidade maior, expõem-nas a alimentos mais industrializados e de baixa qualidade nutricional. Ressalta-se que não há um simples excesso alimentar, mas, principalmente, uma inadequação nutricional.

\section{Considerações finais}

Com base nas informações da presente pesquisa, percebe-se que o Brasil sempre manteve iniciativas na área da SAN, mais ou menos organizadas e em níveis de intensidade que variaram de acordo com cada período histórico, mas que foi a partir da virada do milênio que surgiu um conjunto de ações, políticas públicas e leis que colocaram a SAN num outro patamar, tanto em termos teórico-conceituais quanto de efetividade prática. É a partir desse momento, que o país coloca a SAN e a inclusão social no centro da agenda do governo, ligando políticas macroeconômicas, sociais e agrícolas (FAO, 2014a).

Analisando a evolução da SAN no Brasil, percebe-se claramente que os avanços ocorridos nesta área se deram em função da ação do Estado. Autores como Rocha (2004) sustentam que somente com uma forte intervenção do Estado é possível romper o "ciclo vicioso" e perverso da fome e da pobreza.

Pelo visto e pelas perspectivas colocadas, pode-se concluir que o Brasil caminha na direção da consolidação de um conjunto de políticas públicas na área da SAN, cada vez mais estruturantes, inseridas num contexto maior de desenvolvimento, e que coloca a alimentação como um direito social, onde o Estado brasileiro assume para si essa tarefa de assegurá-lo a todos os cidadãos. Acredita-se que essas estruturas e políticas construídas até então colocam o Brasil, com relação a essa temática, em bases consistentes, capazes de não só preservar os avanços já alcançados como também enfrentar os novos desafios. Nota-se que, na área da SAN, o Brasil vem sabendo combinar ações emergenciais com estruturais, dentro de uma governança compartilhada entre Estado e sociedade civil.

Ressalta-se ainda que a formulação e a implantação das atuais políticas públicas na área de SAN tiveram a participação efetiva de movimentos sociais, religiosos e de organizações da sociedade civil. Segundo Pinheiro (2009a), a história da SAN, no Brasil, nas duas primeiras décadas após sua redemocratização, foi protagonizada pela sociedade civil organizada. Os movimentos, as campanhas, os comitês, os fóruns e as conferências configuram um espaço ímpar de participação direta da população e ajudaram a produzir consensos, alinhar decisões e potencializar ações. Isso torna a trajetória da SAN no Brasil intimamente ligada ao trabalho dos mais variados órgãos civis e governamentais. 
Promover a SAN em bases teórico-metodológicas, como o Brasil vem implantando atualmente, não é tarefa fácil, diante de um país de dimensões continentais, ainda bastante marcado por desigualdades sociais e pela presença de setores da sociedade que ainda têm dificuldades em discutir temas como a fome e a pobreza. Talvez a saída do mapa mundial da fome possa, de alguma forma, contribuir para a superação do debate reducionista e preconceituoso, muitas vezes, ainda presente nas discussões que envolvem a questão da fome e da pobreza.

Conforme Villa Real (2011), um dos maiores méritos do Brasil foi dar, no último período, uma atenção maior à questão da SAN. A opção de colocar o problema da fome e da pobreza na agenda política nacional, tratando-o como tema inadiável, fez com que o país o priorizasse de forma integrada a uma estratégia de inclusão social, de desenvolvimento econômico e de soberana nacional.

Por fim, ressalta-se a importância de se pesquisar mais acerca da transição alimentar e nutricional e de novos padrões de consumo e produção, procurando evidenciar como esses temas podem se relacionar, bem como analisar empiricamente experiências concretas relacionadas a SAN e os mercados institucionais de alimentos.

\section{Referências}

ARANCIBIA, F. E. R. Consumo Sustentável: padrões de consumo da nova classe média brasileira. 2012. 144f. Dissertação (Mestrado em Desenvolvimento Sustentável) - Universidade de Brasília, Brasília, 2012.

BARROS, R. R. Consumo de alimentos industrializados e fatores associados em adultos e idosos residentes no Município de São Paulo. 2008. 174f. Dissertação (Mestrado em Saúde Pública) - Faculdade de Saúde Pública, Universidade de São Paulo, São Paulo, 2008.

BRASIL. Lei $n^{\circ} 11.346$, de 15 de setembro de 2006. Cria o Sistema Nacional de Segurança Alimentar e Nutricional - SISAN com vistas em assegurar o direito humano à alimentação adequada e dá outras providências. Diário Oficial [da] União, Brasília, 18 set. 2006.

CAISAN - Câmara Interministerial de Segurança Alimentar e Nutricional. Plano Nacional de Segurança Alimentar e Nutricional: 2012/2015. Brasília, 2011.

CASTRO, J. Geografia da fome. 10. ed. revista. Rio de Janeiro: Antares, 1984.

CEPIS. Centro de Educação Popular do Instituto Sedes Sapientiae. História da sociedade. São Paulo, 2004.

CONSEA. Conselho Nacional de Segurança Alimentar e Nutricional. I Conferência Nacional de Segurança Alimentar. Brasília, 1995.

CHRISTENSEN, T. N. S. História do Rio Grande do Sul em suas origens missioneiras. ljuí: Unijuí, 2001.

Santa Rosa: histórias e memórias. Santa Rosa: Palloti, 2008. 
FAO. Organização das Nações Unidas para a Alimentação e a Agricultura. O estado de segurança alimentar e nutricional no Brasil: um retrato multidimensional. Brasília: FAO, 2014.

. O Estado da Insegurança Alimentar no Mundo. Roma: FAO, 2014a.

INSTITUTO CIDADANIA. Projeto Fome Zero: uma proposta de política de segurança alimentar para o Brasil. Versão 3. São Paulo: Instituto Cidadania, 2001.

2001 .

. Projeto Fome Zero: documento-síntese. São Paulo: Instituto Cidadania,

LEÃO, M. (Org.). O Direito Humano à Alimentação Adequada e o Sistema Nacional de Segurança Alimentar e Nutricional. Brasília: ABRANDH, 2013.

IPEA. Instituto de Pesquisa Econômica Aplicada. Políticas sociais: acompanhamento e análise. v. 1, n. 17. Brasília: IPEA, 2008.

. A trajetória histórica da segurança alimentar e nutricional na agenda política nacional: projetos, descontinuidades e consolidação (Texto para Discussão no 1953). Brasília: IPEA, 2014.

IBGE. Instituto Brasileiro de Geografia e Estatística. PNAD Segurança alimentar 2004/2009. Brasília: IBGE, 2010.

MACEDO, D. C. et al. A construção da política de segurança alimentar e nutricional no Brasil. Rev. Simbio-Logias, v. 2, n. 1, p. 31-46, 2009.

MAZOYER, M.; ROUDART, L. História das agriculturas no mundo: do neolítico à crise contemporânea. São Paulo: UNESP; Brasília: NEAD, 2010.

MIELITZ, C. Dez anos de PAA e a constituição de uma estratégia nacional de Segurança Alimentar. In: BRASIL. Ministério do Desenvolvimento Social e Combate à Fome. PAA: 10 anos de aquisição de alimentos. Brasília: MDS, 2014.

MORAIS, L.; BORGES, A. (Orgs.). Novos paradigmas de produção e consumo: experiências inovadoras. São Paulo: Instituto Pólis, 2010.

MOURA, M. C. O. Cultura alimentar: alguns elementos para a formulação de um programa de segurança alimentar. In: Fome Zero. Educação Cidadã: novos atores, nova sociedade. Brasília: Setor de Mobilização Social do Fome Zero, 2004.

MÜLLER, A. L. A construção das políticas públicas para a agricultura familiar no Brasil: o caso do Programa de Aquisição de Alimentos. 2007. 128 f. Dissertação (Mestrado em Desenvolvimento Rural) - Faculdade de Ciências Econômicas, Universidade Federal do Rio Grande do Sul, Porto Alegre, 2007.

MDS. Ministério do Desenvolvimento Social e Combate à Fome. Cadernos de Estudos Desenvolvimento Social em Debate, n. 2. Brasília: Secretaria de Avaliação e Gestão da Informação, 2005. 
PAULI, J.; ROSA, E. (Orgs.). Consumo crítico, solidário e coletivo. Passo Fundo: Clio Livros, 2004.

PINHEIRO, A. R. O. Análise histórica do processo de formulação da Política Nacional de Segurança Alimentar (2003-2006): atores, idéias, interesses e instituições na construção do consenso político. 2009. 234f. Tese (Doutorado em Política Social) Instituto de Ciências Humanas, Universidade de Brasília, Brasília, 2009.

PINHEIRO, S. Cartilha da biodiversidade. Porto Alegre: La Salle, 1999a.

. Cartilha da reforma agrária. Porto Alegre: La Salle, 1999b.

. Cartilha das sementes. Porto Alegre: La Salle, 1999.

. Cartilha dos agrotóxicos. Porto Alegre: La Salle, 1998.

ROCHA, M. (Org.). Segurança alimentar: um desafio para acabar com a fome no Brasil. São Paulo: Fundação Perseu Abramo, 2004.

ROMÃO, M. M. Produção Agroecológica Integrada e Sustentável (PAIS), uma tecnologia social para construção da segurança alimentar. In: MORAIS, L.; BORGES, A. (Orgs.). Novos paradigmas de produção e consumo: experiências inovadoras. São Paulo: Instituto Pólis, 2010.

TURPIN, M. E. A alimentação escolar como vetor de desenvolvimento local e garantia de segurança alimentar e nutricional. 2008. 160 f. Dissertação (Mestrado em Desenvolvimento Econômico) - Instituto de Economia da UNICAMP, São Paulo, 2008.

VILLA REAL, L. C. A problemática da produção e consumo de alimentos e o lugar da alimentação escolar: uma revisão de literatura. 2011. 121 f. Dissertação (Mestrado em Economia) - Faculdade de Ciências Econômicas da UFRGS, Porto Alegre, 2011.

ZIMMERMANN, S. A. Políticas públicas e os espaços democráticos: um olhar sobre a III Conferência Nacional de Segurança Alimentar e Nutricional - Brasil. Revista Desenvolvimento em Questão. Ijuí: Unijuí, ano 6, n. 12, jul./dez. 2008. 